\section{High precision chi-square and normal curve integration}

\section{LOUIS WOOD \\ University of Arkansas, Little Rock, Arkansas}

The routine discussed in this paper determines chisquare and normal curve probabilities in a manner similar to a technique introduced by Wood and Wood (1985). Their program integrates the $t$ density function to provide two-tailed $t$ probabilities with five decimal place accuracy, up to a maximum of $115 \mathrm{df}(\mathrm{n})$. The level of accuracy in their technique is achieved via an algorithm of Simpson's rule. The handling of the large maximum $n$ without computer overflow is achieved by recognizing that, because $n$ is integral in $t$, chi-square, and $F, \Gamma(n / 2)$ is a factorial process. Because $f(t)$ contains $\Gamma[(n+1) / 2] / \Gamma(n / 2)$, common factorial factors are divided out before multiplication, thus reducing the magnitude of the two products and preventing overflow until $n$ exceeds 115 .

The routine presented here (see Appendix) achieves accurate results via application of the same swift algorithm of Simpson's rule in which the chi-square and normal density functions are divided into tiny segments. The areas are then determined and summed (Anton, 1981). Accuracy is provided to a minimum of five decimal places.

The range of numerical integration is not a problem with the normal curve, because this routine accurately finds any specified area bounded by $Z=-6$ and $Z=6$, and having a probability within six decimal places. The range of integration becomes a problem with chi-square bounded by 0 and $\infty$, and for which $\mu=\mathrm{n}$ (Beyer, 1979, p. 522). Nevertheless, with one exception the program exactly evaluates all chi-squares having probabilities from .000001 to .999998 for $1 \leq \mathrm{n} \leq 34$. Where $\mathrm{n}=3$, five place accuracy is maintained.

The Simpson's rule algorithm evaluates a standard version of chi-square (Beyer, 1979, p. 522) that is algebraically manipulated for programming purposes into the following form:

$$
f\left(\chi^{2}\right)=\frac{1}{\sqrt{2^{n}} \cdot \Gamma(n / 2)} \cdot \frac{\left(\sqrt{\chi^{2}}\right)^{n-2}}{(\sqrt{e})^{x^{2}}} .
$$

The left portion is the parametric component requiring only the number of degrees of freedom ( $n$ ) for computation. The right component, having $\chi^{n-2}$ as its numerator, becomes exponentially large when both $n$ and chi-square are large, and computer overflow results. Techniques em-

The author's mailing address is: Department of Psychology, University of Arkansas, 33rd Street and University Avenue, Little Rock, Arkansas 72204. ployed in this program extend the usable range of chisquare and $n$ before overflow occurs.

The program begins by presenting a menu to the user offering a chi-square probability, a normal curve area, or the end of work. If the user selects chi-square, the program requests the number of degrees of freedom. The logical path branches at this point according to $\mathbf{n}$. For $\mathbf{n}=$ 1,3 , or 5 , special subroutines exist. For all other values, a common path is taken beginning with the gamma function subroutine which evaluates $\Gamma(\mathrm{n} / 2)$. Using gamma, the parametric portion of $f\left(\chi^{2}\right)$ is then computed and assigned the variable name $P$.

The logical flow then branches to Line 1000 which begins a subroutine that sets the number of segments (W) into which the density function will be partitioned. All lines with 4-digit numbers are W setters. Generally W increases as function of $n(\mathrm{H}$ in the program) and chisquare (U in the program).

With $\mathrm{P}$ and $\mathrm{W}$ determined, the program begins the Simpson's rule algorithm which computes the area between zero and the user-entered chi-square. The significance figure, 1 - Area, is also calculated. Finally the results are printed on the screen and the menu reappears.

For all degrees of freedom less than 20 , except $n=$ 1 , the chi-square function is evaluated by Simpson's rule exactly as shown, because no overflow occurs for the maximum, usable values of $\mathbf{n}$ and chi-square. Specifically for $\mathrm{n}=19$ and $\chi^{2}=61.06947$, the computed probability is 0.999998 which is the limiting accuracy value of the routine. Beyond $n=19$, however, special techniques are required to prevent overflow.

When $n>19$, the density function is evaluated as follows:

$$
f\left(\chi^{2}\right)=\frac{1}{\sqrt{2^{\mathbf{n}}} \cdot \Gamma(\mathrm{n} / 2)} \cdot \frac{\left(\sqrt{\chi^{2}}\right)^{\mathrm{n}-20}}{(\sqrt{\mathrm{e}})^{\chi^{2}}}\left(\sqrt{\chi^{2}}\right)^{18},
$$

so that the chi-square portion resolves to

$$
\frac{\chi^{\mathrm{n}-20}}{(\sqrt{\mathrm{e}})^{\chi^{2}}}\left(\chi^{18}\right)
$$

The effect is that for any $n>19$, the right (i.e., $\chi^{2}$ ) portion of the function still reduces to $\chi^{n-2} /(\sqrt{\mathrm{e}}) x^{2}$, but for programming purposes an advantage has been achieved. Rather than directly computing $\chi^{\mathrm{n}-\mathrm{z}}$ which produces overflow when $\chi$ and $\mathbf{n}$ are large, this arrangement computes $\chi^{\mathrm{n}-20} /(\sqrt{\mathrm{e}})^{x^{2}}$ first. When that fraction is determined, it is then multiplied by $\chi^{18}$. Without this modification, overflow occurs where $\mathrm{n}=\chi^{2}=29$; with it the range is extended up to $\mathrm{n}=\chi^{2}=37$. The gain of $8 \mathrm{df}$ is not trivial, because each increase of $1 \mathrm{df}$ results in an exponential increment in $\chi^{\mathrm{n}-20}$.

The $n=3$ and $n=5$ density functions were mentioned 
as special cases and are in the sense that their graphs exhibit extreme curvature. Because of this, many area segments are required for accurate probability determinations. Lines 1030-1035 set $\mathrm{W}$ for $\mathrm{n}=5$ and Lines 1040-1075 determine $W$ for the curvy $3 \mathrm{df}$ chi-square. These two functions also require double precision determinations of the parametric portion of $f\left(\chi^{2}\right)$, and these are written into the routine. The combination of a large number of segments and double precision parameters results in very slow running times.

A complication of numerical integration of $f\left(\chi^{2}\right)$ is that, when $n=1, f\left(\chi^{2}\right)$ is asymptotic to the vertical axis and cannot be integrated from zero to a positive value. Resolution comes from the fact that $\mathrm{z}^{2}=\chi^{2}$ where $\mathrm{n}=1$, and the two roots of chi-square are the normal variates $\mathrm{Z}$ and $-\mathrm{Z}$. A two-tailed test, therefore, of the unit normal distribution provides an exact significance test for one degree of freedom chi-squares. Thus when $\chi^{2}(n=1)$ is entered, the positive square root is extracted and defined as Z. Simpson's rule is applied to determine the normal curve area between the $\mu=0$ and $\mathrm{Z}$. The area is doubled, yielding the area between $\chi^{2}=0$ and the userentered value. Subtracting that area from one gives the significance test for the one degree of freedom chi-square.

Because the normal curve subroutine is an integral component of the chi-square program, a normal curve areafinding option has been included. When the user responds to the menu by selecting "Normal Curve,"' the computer presents instructions, which state that the routine finds the area between two $\mathrm{Z}$ scores. The algebraic value of the smaller $\mathrm{Z}$ is requested, followed by a request for the algebraic value of the larger. The normal curve area between the $\mathrm{Z}$ scores is displayed first and for purposes of hypothesis testing the total area beyond that subtended by the $\mathrm{Z}$ scores is also displayed. The user simply enters the negative of a $Z$ involved in a significance test (e.g., Fisher's $Z^{\prime}$ for correlation) and then the positive value of $\mathrm{Z}$ : The two-tailed probability appears.

High accuracy is the primary priority of the routine and is achieved at some cost in running time, especially for the $n=3$ and the $n=5$ cases. Except for $n=3$, results are accurate to six decimal places from $p=0.000001$ to $p=0.999998$, over the range from $n=1$ to $n=34$. Beyond $34 \mathrm{df}$, the accuracy continues, but the range is restricted by overflow; for example, $\chi^{2}=85$ with $n=$ 36 is correctly assigned a probability of 0.999992 , but when $\chi^{2}=89.324(p=0.999998)$ is entered, overflow occurs. For the three degrees of freedom case, an enormous number of segments are required to provide five decimal place accuracy, and running times in the 5-20min range are the rule. Even very small chi-squares run slowly. Accuracy is maintained, however, over the entire range from $p=0.00001$ to $p=0.99998$.

The accuracy of this program is so high that chi-square values taken from tables and having two, three, or even four decimal places when tested, often fail to result in the tabled probability figure. Three-digit tables, for example, cite $\chi^{2}=5.991$ as the $p=.05$ value for $2 \mathrm{df}$. The pro- gram displays a significance figure $(1-\mathrm{A})$ of 0.050012 , for 5.991, and that is correct. When $\chi^{2}=5.991465$ is run, the figures $\mathrm{A}=0.950000$ and $1-\mathrm{A}=0.050000$ appear.

The TRS-80 Model 4 microcomputer has a Z-80A microprocessor with a clock speed of $4 \mathrm{MHz}$, which gives running times ranging from $6 \mathrm{sec}$ to $60 \mathrm{sec}$ in all cases except $n=3$ and $\chi^{2}>0.5$ and $n=5$ and $\chi^{2} \geq 17$. The latter run in $2 \mathrm{~min}, 8 \mathrm{sec}$, while the former are extremely slow. The program includes running times only for $\mathbf{n}=$ 3 and uses them as a guide. The program runs without modification on the IBM-PC and is noticeably faster than on the TRS-80. The limits at which overflow occurs are slightly higher on the IBM-PC.

On rare occasions a probability is required for larger values of $\mathbf{n}$ and chi-square than the present configuration affords. A significant expansion of the range of the program can be accomplished by rewriting Line 22 as follows.

$22 \mathrm{Y}=\mathrm{P} * \mathrm{SQR}\left(\mathrm{X}^{\Lambda} \mathrm{E} / 2.71828183 \hbar^{\Lambda} \mathrm{X}\right): \mathrm{Y}=\mathrm{Y} * \mathrm{SQR}\left(\mathrm{X}^{\Lambda} 18\right): \operatorname{RETURN}$

Using this expression, overflow first occurs with the $\chi^{2}=$ $n$ test at 44 , and for $n=40$, with this version of Line 22 overflow occurs at $\chi^{2}=78$ on the TRS-80 Model 4 computer. With the listed version, the limit is $\chi^{2}=15$ with $\mathrm{n}=40$. Because this version of Line 22 extracts two square roots rather than the one used in the Appendix, it runs a bit more slowly and on occasion introduces a one-unit error into the sixth decimal place. Users desiring only 5-place accuracy are advised that Line 22 should be replaced with the version above on a permanent basis.

Availability. A listing of the program can be obtained without charge from D. Louis Wood, Department of Psychology, University of Arkansas, 33rd Street and University Avenue, Little Rock, Arkansas 72204.

\section{REFERENCES}

Anton, H. (1981). Calculus. New York: Wiley.

BEYER, W. H. (Ed.). (1979). C R C Standard Mathematical Tables (25th ed.). Boca Raton, FL: C R C Press.

WoOD, D. L., \& WoOD, D. (1985). TINT: A Microsoft BASIC $t$ integration program. Behavior Research Methods, Instruments, \& Computers, 16, 479-480.

\section{APPENDIX}

Listing of Program for Chi-Square and Normal Curve Integration

\footnotetext{
1 C.S

2 CLEAR: DEFINT J, H,M,W

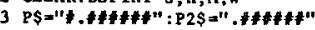

4 PRINT"TYPE YOUR CHOICE BY NUMBER

(1) Chi Square

(2) Normal Curve

(3) End"

5 C\$ INKEYS : IF C\$="'" THEN $S$

6 ON VAL (C\$) GOTO $8,48,65,7$

7 PRINT: PRINT"WRONG KEY PRESSEDI" : PRINT: COTO 2

8 INPUT"ENTER df ": H: IF H>30 THEN DEFDBL D, S, T, X, Y, G

9 PRINT: INPUT"ENTER CHI SQUARE "; U:GOSUB 64

10 IF $H=1$ THEN $Z=S Q R(U): U=Z: L=0: W=90: \operatorname{coro} 23$

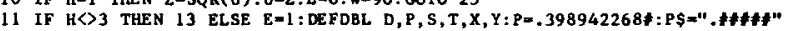

12 P2\$ $=" . * * * * "$; $\cos U B$ B $1040: \cos U B$ B $46:$ GOTO 32

13 IF $\mathrm{H}\langle>5$ THEN 15 ELSE $\mathrm{E}=3$ : DEFDBL $\mathrm{D}, \mathrm{P}, \mathrm{S}, \mathrm{T}, \mathrm{X}, \mathrm{Y}: \mathrm{P}=, 132980756 \#$ : cosuB 1030
} 
14 cosis $45: \operatorname{coto} 32$

15 GOSUB $37: F=1 /(G * \operatorname{SQR}(2-H)): \operatorname{CosUB} 1000:$ RINT

16 IF $\mathrm{H}<20$ THEN E-A-2: $\operatorname{COTO} 32$

$17 \mathrm{~g}=\mathrm{H}-20$

18 $D=0 / W: S=0: T=0: y=0: \cos U B \quad 22: S=S+Y: X=0: \cos U B \quad 22: S=S+Y: H=W / 2$

19 FOR $J=1$ TO $M: X=(2 * J-1) * D: \operatorname{Cos} U E 22: T=T+Y: R E X T: S=S+4 * T: T=0: M=H-1$

20 FoR $J=1$ TO $M: X=2 * J * D: \operatorname{Cos} U B \quad 22: T=T+Y: M E X T: S=S+2 \star T$

$21 \quad A=D * S / 3:$ coto 58

$22 Y=P * S Q R\left((X-E / 2,71828183 *-X) * X^{-} 18\right): R E T U R N$

$23 \mathrm{D}=(\mathrm{U}-\mathrm{L}) / W: S=0: T=0: X=L: \operatorname{Cos} U B$ B $31: S-S+Y: X=U: \cos U B \quad 31: S-S+Y: M=W / 2$

24 FOR $J=1$ TO $X: X=L+(2 * J-1) * D: \cos U B$ $31: T=T+X: N E X T: S=S+4 \star T: T=0: M=-1$

25 FOR $J=1$ TO $M: X=2 * J * D+1: \cos U B$ B $31: T=T+Y: M E X T: S=S+2 * T$

$26 A=D * S / 3: A R=2 * A:$ ON VAL (CS) COTO 58,27

27 PRINT"The Area Between 2 Scores Is "USING PS;A

28 PRINT" "

29 PRINT"The Suw of The Areas Beyond The Specified 2 's Is "USING PS;1-A

30 PRINT" ": COTO

$31 Y=.398942 / 1.64872-(X * X):$ RE TUR

$32 \mathrm{D}=\mathrm{U} / \mathrm{W}: \mathrm{S}=0: \mathrm{T}=0: \mathrm{X}=0: \cos U B \quad 36: S=S+Y: X=U: \cos U B \quad 36: S=S+Y: M=\mathrm{W} / 2$

33 FOR $\mathrm{J}=1$ TO $\mathrm{M}: \mathrm{X}=(2+\mathrm{J}-1) \neq \mathrm{D}: \operatorname{COSUB} 36: \mathrm{T}=\mathrm{T}+\mathrm{Y}: \mathrm{NEXT}: \mathrm{S}=\mathrm{S}+4 * \mathrm{~T}: \mathrm{T}=0: \mathrm{M}=\mathrm{H}-1$

34 FOR $J=1$ TO $M: X=2 \star J * D: \operatorname{COSUB} 36: T=T+Y: N E X I: S=S+2 * T$

$35 A=S \star D / 3:$ :OTO 58

$36 \quad Y \rightarrow P \star S Q R(X-E / 2.7182818 *-x): R E T U R N$

37 IF H<S THEN $G=1:$ RETURN

$38 \mathrm{C}-1:$ IF $\mathrm{H} / 2$ >INT $(\mathrm{H} / 2)$ THEN 40

$39 \mathrm{M}=\mathrm{H} / 2-1:$ FOR $\mathrm{J}=$ ! TO $\mathrm{M}: \mathrm{G}=\mathrm{G}$ J J:NEXT: RETURH

$40 \mathrm{M}=\mathrm{INT}(\mathrm{H} / 2): M=2 * H-1$

41 FOR J=1 TO M STEP $2: G=G * J / 2:$ NEXT

$42 G=G * 1.7724544:$ RETURN

43 PRINT"

44 PRINT"'THIS COMPUTATION IS SOMEWHAT SLOW !": RETURN

45 PRINT:PRINT "THIS COMPUTATION IS SLOW :": RETURN

46 PRINT"I HIS C OMPUTATION TAKE 5 " RT "MINUTE

47 PRINT" "I PETURN

48 PRINT"NORMAL CURVE

49 PRINT" "
30 PRINT"This Progran Conputes Areas Under The Unit Noral Curve Between Two"

INF INITY IET $z=-6$ USE $z$ - 6 TO INDICATE ";

53 PRINT"POSITIVE INF INITY."

54 PRINT: INPUT"Enter The Sasller 2 Algebraically ";

36 IF $L<0$ AND $U>0$ AND ABS $(U-L)>6$.

37 cosvB $64:$ COTO 23

58 PRINT

59 CLS:IF H=1 TEIEN A=AR

60 PaINT"The Areo Between Zero And Chi Squere Is "USIMG P\$;A

61 PRINT"The Probability of Chance Occurrence of A Larger Chi square Is "; 62 PRINT USING P2S:1-A

63 PRINT" ": COTO

64 PRINT:PRINT"C O H P U T I N G I": BETURN

65 END

1000 IF H<10 AND U>25 THEN W=480: COSUB 43: RETURN

1005 IF HC10 AND $U>15$ THEN W=320: COSUB 42 : RETURN

1020 IF $\mathrm{K}<12$ AND U>10 THEN W-110: RETURH

1015 IF HC31 AND U<31 THEN W-60: RETURN

1020 IF $B<31$ AND $0<71$ THEN W-300: COSUB 42 : BETURN

1025 W $=480$ : COSUB 43 : RETURH

1030 IF $U<17$ THEN $W=576$ ELSE $W=1200$

1035 RETURN

1040 IF UK.5 TEEN W-640: RT-.85: EETURN

1045 IF $U<4$ TIEN $W=3600: \mathbf{m}=4.8$ : RETURN

1050 IF U 6 THEN $W=4800$ : :T $=6$.S: : RETURN

1055 IF $U<B$ THEN $W=6400: R T=8.33:$ RETUR

1060 IF U<9.4 THEN W-7520: RT=10: EETURN

1065 IF UC11.4 THEN H=9200: RT-16.1: RETURN

1070 IF U<16.3 THEN W=12000: RT-20.82: RETURN

$1075 \mathrm{H}=18000: \mathrm{RT}=23.59: \mathrm{RE}$ TURN

(Revision accepted for publication May 8, 1985.) 